\title{
Pengendali Suhu Purwarupa Pengering Gabah Berbasis Mikrokontroler Menggunakan Metode Kendali PI
}

\section{Microcontroller-Based Temperature Control of Grain Dryer Prototype Using Pi Control Method}

\author{
Munawar Agus Riyadi ${ }^{1 *}$, Umair Al-Anshory ${ }^{2}$, Iwan Setiawan ${ }^{3}$ \\ ${ }_{1,2,3}$ Departemen Teknik Elektro, Universitas Diponegoro \\ J1. Prof. Sudharto, SH, Kampus UNDIP Tembalang, Semarang 50275, Indonesia \\ munawar@elektro.undip.ac.id*
}

\begin{abstract}
Abstrak - Proses pengeringan gabah di Indonesia umumnya dilakukan dengan pemanasan matahari di luar ruang, sehingga metoda pengeringan tersebut sangat tergantung pada musim dan cuaca. Untuk mengatasi masalah tersebut diperlukan sebuah alat pengering gabah yang memiliki sistem kendali suhu agar dapat melakukan pengeringan sampai dengan kadar air yang diinginkan dengan suhu pemanasan yang optimal. Pada penelitian ini dirancang purwarupa sistem pengendalian suhu pengering gabah menggunakan sensor DHT22 sebagai pengukur suhu udara, heater sebagai elemen pemanas, dan mikrokontroler ATMega328P sebagai pengendali. Metoda kendali yang digunakan untuk mengendalikan suhu prototype pengering gabah adalah metoda kendali Proportional Integral (PI). Parameter kendali PI diperoleh melalui metoda tuning Ziegler Nichols 1 dengan nilai $\mathrm{Kp}=186,16$ dan $\mathrm{Ti}=33$,3. Pengujian sistem pengendali menggunakan parameter kendali PI ini menunjukkan kinerja yang lebih baik dibandingkan pemanasan matahari karena mampu mencapai dan mempertahankan suhu referensi yang diinginkan serta dapat mengatasi gangguan yang terjadi dalam rentang suhu yang aman.
\end{abstract}

Kata kunci: Purwarupa pengering gabah, sensor suhu DHT22, mikrokontroler ATmega328P, Proportional Integral (PI)

\begin{abstract}
Grain drying process in Indonesia is generally carried out by outdoor sun heating, which is very dependent on the season and weather. To overcome this problem, grain dryer with temperature control system is required to dry up to the desired water content with optimal heating temperature. In this study, grain dryer prototype was designed using DHT22 temperature sensor, heater, and ATMega328P microcontroller. The Proportional Integral (PI) control method was applied to control the temperature of the grain dryer prototype. PI parameters were obtained through Ziegler Nichols 1 tuning method with values of $\mathrm{Kp}=186.16$ and $\mathrm{Ti}=33.3$. The system testing results show better performance than sun heating as it is able to achieve and maintain the plant temperature at desired references and can overcome the disturbances within safe temperature.
\end{abstract}

Keywords: Grain dryer prototype, DHT22 temperature sensor, ATmega328P microcontroller, PI control method

TELKA, Vol.5, No.1, Mei 2019, pp. 74 82

ISSN (e): 2540-9123

ISSN (p): 2502-1982 


\section{Pendahuluan}

Proses pengeringan gabah di Indonesia umumnya dilakukan dengan pemanasan matahari (sun-dryer floor). Gabah dikeringkan di bawah sinar matahari di luar ruang. Namun metode pengeringan tersebut sangat tergantung pada musim dan cuaca. Pada musim kemarau lama waktu pengeringan berkisar antara $16-24$ jam, sedangkan pada musim penghujan lama waktu pengeringan naik menjadi 24 - 32 jam [1]. Hal ini mengurangi efektivitas produksi gabah serta kualitas gabah tidak terjaga akibat cuaca yang tak menentu. Untuk mengatasi masalah tersebut telah dikembangkan beberapa alat pengering untuk mempermudah proses pengeringan padi, contohnya pengering tipe bak (batch dryer) [2], [3], rotary [4], fluidisasi [5] atau dengan pembekuan (freeze) [6]. Masing-masing tipe pengering memiliki kelebihan dan kekurangan, sesuai kebutuhan pengeringan yang dipengaruhi kapasitas dan bahan yang hendak dikeringkan. Alat pengering tipe batch bekerja dengan memasukkan gabah ke dalam ruang dengan suhu tinggi agar pengeringan berjalan lebih cepat dan efektif [2]. Kecepatan rata-rata pengeringan tipe mechanical dryer adalah 1,1-1,9\% kadar air per jam, lebih tinggi daripada pengeringan sun-dryer dengan nilai kecepatan rata-rata 0,3-0,5\% kadar air per jam [1]. Tetapi, sebagian besar batch dryer masih menggunakan kendali tipe on-off. Hal tersebut membuat pengeringan dilakukan dengan dasar waktu pemanasan, bukan berdasarkan target kadar air yang diinginkan. Selain itu suhu pemanasan yang terjadi tidak dapat dikendalikan secara tepat dan suhu yang terlalu tinggi dapat merusak gabah sedangkan suhu yang terlalu rendah membuat waktu pemanasan menjadi lebih lama. Oleh karena itu diperlukan sebuah sistem kendali suhu di dalam alat pengeringan gabah agar dapat melakukan pengeringan sampai dengan kadar air yang diinginkan dengan suhu pemanasan yang optimal.

Pada sistem pengendalian suhu terdapat beberapa metoda kendali yang digunakan untuk mengendalikan keluaran proses dan mengurangi gangguan. Kendali Proportional Integral (PI) merupakan kendali yang sering dijadikan pilihan karena relatif sederhana namun akurat [7]-11]. Metoda kendali PI telah digunakan untuk mengatur suhu pada alat pengering kertas [7], pengering kayu [8] maupun oven otomatis ikan salai [9]. Kendali PI juga diterapkan untuk pengendalian suhu pada kasus pembuatan sirup buah otomatis dengan metode tuning Ziegler Nichols, yang mampu mencapai setting point dengan cukup cepat dan stabil [10]. Perbandingan metode kendali proporsional (P), PI, dan Proporsional-Integral-Derivatif (PID) telah dilakukan untuk mengendalikan suhu pada boiler, dimana kendali PI memberikan unjuk kerja terbaik karena mampu menghilangkan galat pada keadaan tunak [11]. Berdasarkan beberapa penelitian terdahulu tersebut, metoda kendali yang dipilih dalam penelitian ini adalah metode kendali PI karena mampu mengendalikan perubahan suhu mencapai referensi yang diinginkan serta mampu mengurangi gangguan yang terjadi.

Pada makalah ini, disajikan rancangan suatu pengendalian suhu dan desain perangkat keras pada purwarupa pengering gabah menggunakan metode kendali PI berbasis mikrokontroler. Bagian kedua makalah ini menjelaskan metode perancangan purwarupa dan sistem kendali. Penalaan parameter PI dihasilkan dari eksperimen bump test pada proses First Order Plus Dead Time (FOPDT) berdasar metode Ziegler Nichol [12]. Bagian ketiga menjelaskan cara pengujian beserta hasil yang diperoleh beserta analisis dari hasil. Bagian terakhir adalah kesimpulan dari hasil penelitian ini.

\section{Metode Penelitian}

Rancangan perangkat keras pada purwarupa pengering gabah ditunjukkan pada Gambar 1. Plant pengering gabah sebagai plant utama merupakan tempat untuk pengeringan gabah. Di dalam plant, terdapat perangkat pemanas, kipas pemanas, kipas exhaust, dan sensor DHT22 sebagai sensor pendeteksi suhu dan kelembaban ruangan pengering gabah. Panas yang dihasilkan pemanas dapat diatur dengan cara mengatur tegangan masukan sesuai sinyal kendali dari PI. Pemanas yang digunakan memiliki spesifikasi daya 600 watt, tegangan $220 \mathrm{~V}$, frekuensi $50 \mathrm{~Hz}$, dan arus 2 A. Kipas pemanas ditambahkan sebagai penyebar aliran udara pada ruangan pemanas sehingga panas di dalam plant pengering gabah lebih merata. Kipas yang digunakan memiliki spesifikasi tegangan $12 \mathrm{~V}$ dan arus 0,14 A. Selain itu, terdapat kipas exhaust (keluaran) untuk 
pembuangan udara lembab, dengan spesifikasi tegangan $12 \mathrm{~V}$ dan arus 0,065 A. Mikrokontroler ATMega328P digunakan sebagai unit pengendali untuk mengaplikasikan kendali open loop, Kendali PI, dan mengirim data referensi dan data sensor ke komputer mini untuk keperluan pemantauan dan tampilan dalam bentuk LCD (liquid crystal display).

Kendali PI digunakan untuk mengatur suhu purwarupa pengering gabah padi sesuai dengan temperature optimal yang diinginkan yaitu di bawah $45^{\circ} \mathrm{C}$ [13]. Penentuan parameter kendali PI (Kp dan $\mathrm{Ti}$ ) dilakukan melalui eksperimen bump test dengan mengirimkan perubahan sinyal tangga $u(t)$ secara manual melalui human-machine interface (HMI) [12]. Gambar 2 menunjukkan blok diagram peracangan kendali PI.

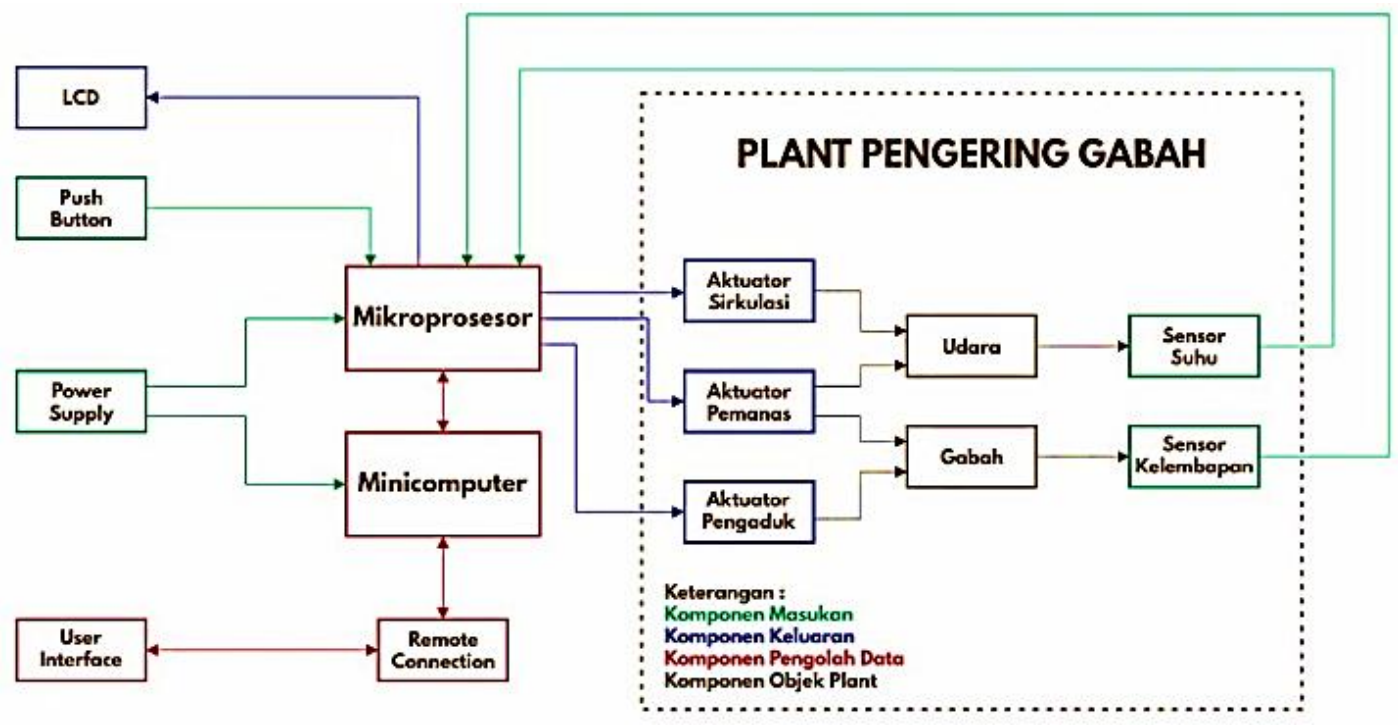

Gambar 1. Blok diagram sistem pengering gabah.

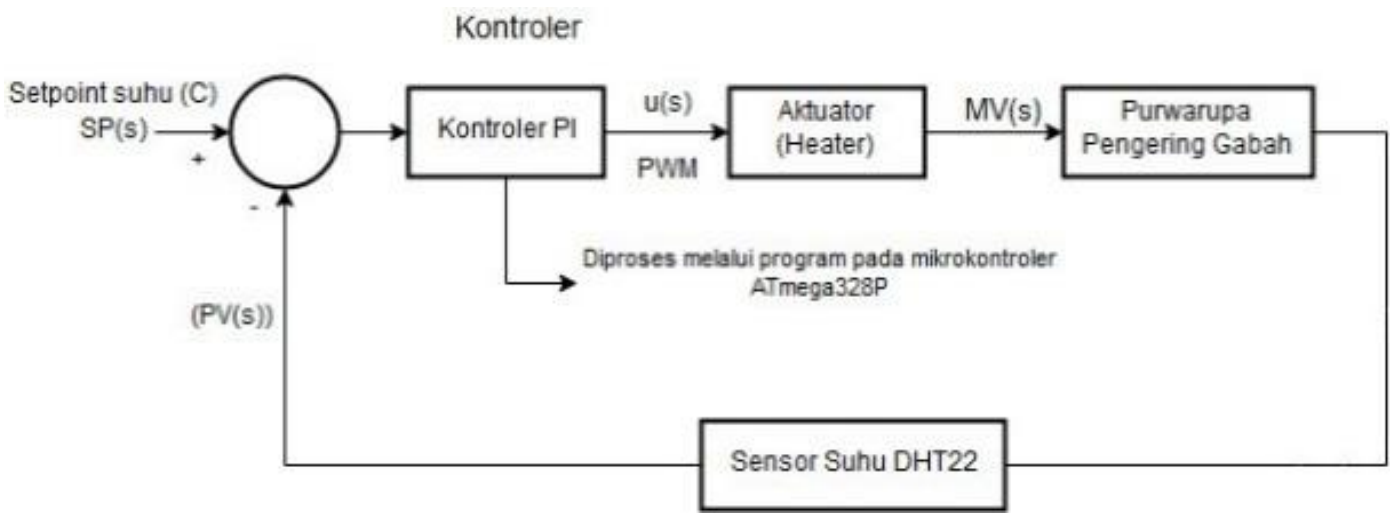

Gambar 2. Diagram blok perancangan kendali PI. 

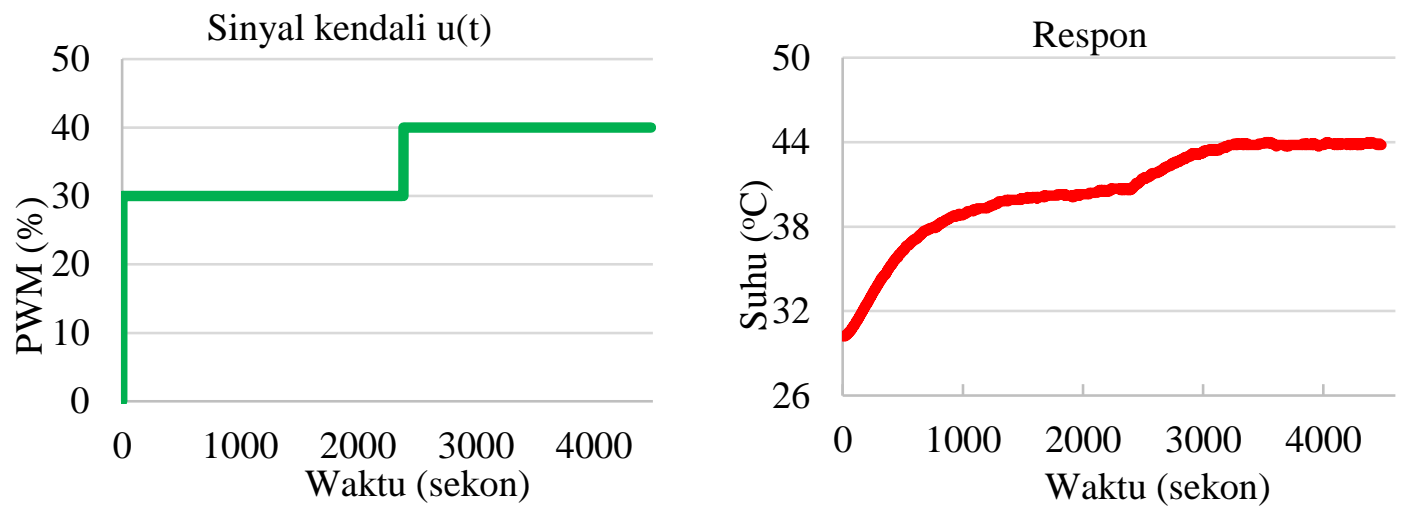

Gambar 3. Hasil dari eksperimen bump test dengan perubahan u dari $30 \%$ menjadi $40 \%$.

Eksperimen bump test pada perancangan kendali PI dilakukan dengan cara mengirimkan perubahan nilai $u(t)$ yang berupa nilai PWM dari $30 \%$ menjadi $40 \%$ melalui interface. Eksperimen bump test pada perancangan ini dilakukan pada kondisi suhu awal purwarupa pengering gabah padi $30^{\circ} \mathrm{C}$. Hasil dari eksperimen bump test dengan perubahan $\mathrm{u}(\mathrm{t})$ dari $30 \%$ menjadi $40 \%$ ditunjukkan pada Gambar 3.

Berdasarkan pengujian pada Gambar 3, dapat dilihat bahwa keluaran proses bersifat stabil dan dapat mencapai kondisi tunak ketika diberi perubahan nilai $u(t)$. Dengan demikian, model proses yang digunakan merupakan model self regulating atau model FOPDT [12]. Parameter kendali PI dapat dicari dengan menentukan parameter-parameter model FOPDT sebagai berikut:

a. Waktu keterlambatan transportasi $(\mathrm{L})=10$ detik.

b. Waktu proses $(\mathrm{T})=827$.

c. Gain statis proses $(\mathrm{K})=0,4$.

Berdasarkan ketiga parameter FOPDT yang diperoleh, dapat ditentukan nilai dari parameter kendali PI menggunakan metode Ziegler Nichols 1 sebagai berikut [12]:

$$
\begin{gathered}
K_{p}=\frac{0,9 T}{K . L} \\
T_{i}=3,33 \times L
\end{gathered}
$$

Dengan memasukkan nilai-nilai T, K dan L, diperoleh nilai-nilai $K p=\frac{0,9 * 558}{0,34 * 10}=147,70$ dan $T_{i}=3,33 \cdot 10=33,3$. 


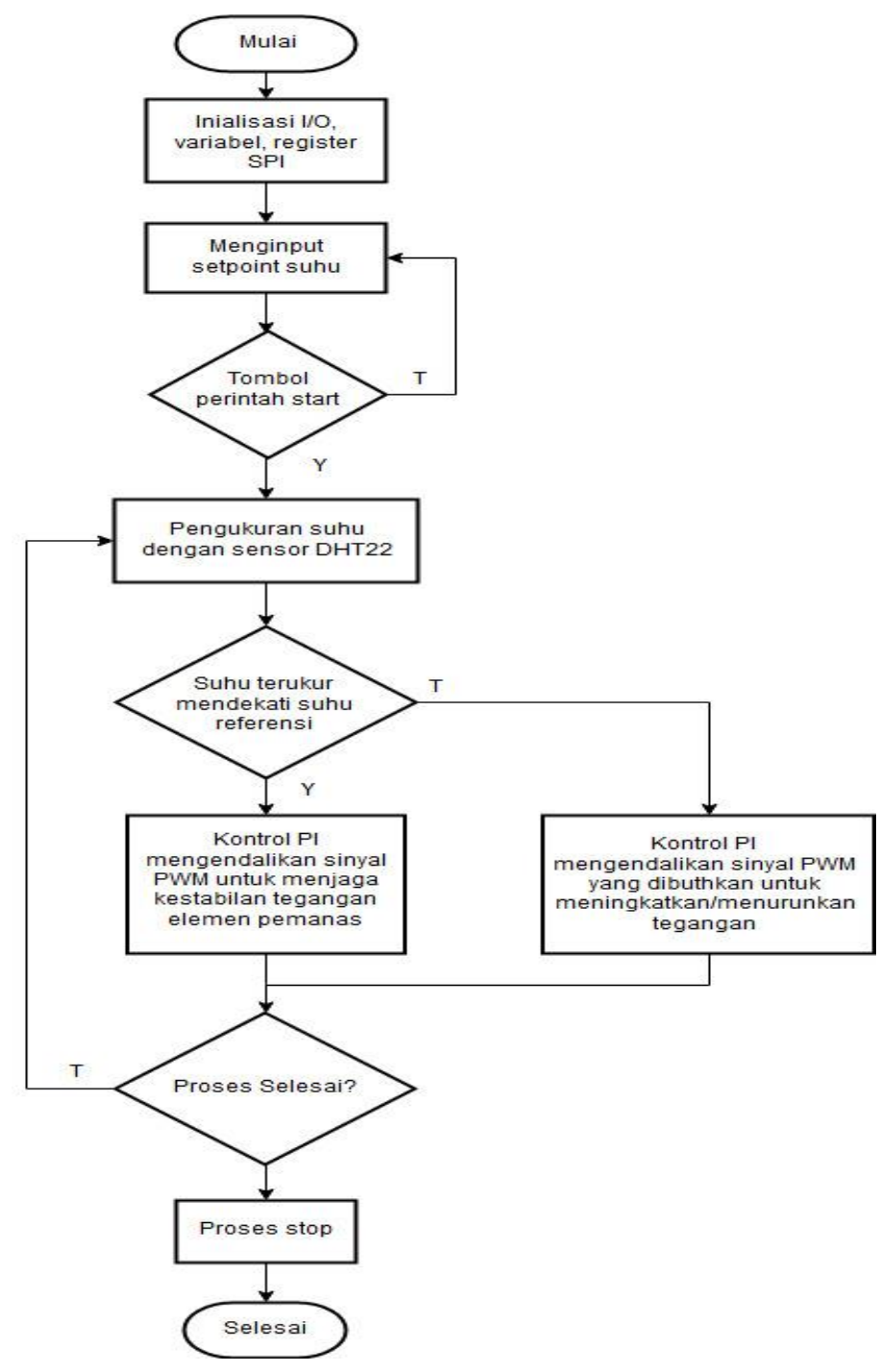

Gambar 4. Diagram alir sistem kendali suhu.

Algoritma dan diagram alir keseluruhan dari sistem kendali suhu pada purwarupa pengering gabah ditunjukkan pada Gambar 4. Urutan prosesnya yaitu sebagai berikut:

a. Mulai

b. Inisialisasi masukan/keluaran, variabel, dan register SPI

c. Masukan data berupa nilai setpoint suhu.

d. Jika perintah start diterima maka dilanjutkan ke proses close loop pengendalian suhu, jika tidak maka kembali ke algoritma c.

e. Pengukuran suhu dengan sensor DHT22

f. Jika suhu terukur mendekati setpoint suhu maka kendali PI mengendalikan sinyal PWM untuk menjaga kestabilan tegangan elemen pemanas, jika tidak maka kendali PI mengendalikan sinyal PWM yang dibutuhkan untuk meningkatkan atau menurunkan tegangan.

g. Jika proses selesai maka memasukkan perintah stop, jika tidak maka kembali ke algoritma e.

h. Selesai 


\section{Hasil dan Pembahasan}

\subsection{Pengujian Sensor DHT22}

Pengujian sensor DHT22 dilakukan dengan membandingkan pembacaan suhu sensor DHT22 dengan termometer digital. Hasil pengujian sensor DHT22 ditunjukkan pada Tabel 1.

Tabel 1. Pengujian sensor suhu DHT22.

\begin{tabular}{cccc}
\hline No. & Sensor DHT22 $\left({ }^{\circ} \mathrm{C}\right)$ & Suhu Termometer $\left({ }^{\circ} \mathrm{C}\right)$ & Error $\left({ }^{\circ} \mathrm{C}\right)$ \\
\hline 1 & 40 & 39,9 & 0,1 \\
2 & 40,5 & 40,6 & 0,1 \\
3 & 41 & 41,2 & 0,2 \\
4 & 41,5 & 41,8 & 0,3 \\
5 & 42 & 42,4 & 0,2 \\
6 & 42,5 & 42,7 & 0,2 \\
7 & 43 & 43,1 & 0,1 \\
8 & 43,5 & 43,8 & 0,3 \\
9 & 44 & 44,3 & 0,3 \\
10 & 44,5 & 44,9 & 0,4 \\
\hline \multicolumn{3}{c}{ Error } \\
\multicolumn{2}{c}{ Error rata-rata } \\
\hline \multicolumn{3}{c}{} \\
\hline
\end{tabular}

Berdasarkan hasil pengujian sensor suhu DHT22 pada Tabel 1, dapat dilihat bahwa pembacaan suhu oleh sensor cukup akurat dengan rata-rata galat pembacaan suhu adalah $0,21{ }^{\circ} \mathrm{C}$.

\subsection{Pengujian Respon Sistem}

Pengujian respon sistem dilakukan pada beberapa suhu referensi awal purwarupa pengering. Respon yang dihasilkan sistem dengan referensi tetap ditunjukkan pada Gambar 5-7. Berdasarkan hasil respon sistem pada referensi tetap pada Gambar 5, kendali PI mampu mencapai dan mempertahankan keluaran suhu sesuai dengan referensi $38^{\circ} \mathrm{C}$ dengan tanggapan respon transien untuk waktu tunda (Td) sebesar 89 detik, waktu naik (Tr) sebesar 178 detik, waktu puncak (Tp) sebesar 272 detik, waktu penetapan (Ts) sebesar 867 detik, dan maximum overshoot (Mp) yang dihasilkan dapat diperoleh melalui perhitungan dengan $(2.15)$ adalah $8,68 \%\left(3,3^{\circ} \mathrm{C}\right)$. Pada referensi $40{ }^{\circ} \mathrm{C}$, tanggapan respon transien ditunjukkan pada Gambar 6, dengan waktu tunda (Td) sebesar 95,5 detik, waktu naik (Tr) sebesar 191 detik, waktu puncak (Tp) sebesar 263 detik, waktu penetapan (Ts) sebesar 1146 detik, dan maximum overshoot (Mp) yang dihasilkan dapat diperoleh melalui perhitungan dengan (2.16) adalah $9 \%\left(3,6^{\circ} \mathrm{C}\right)$. Sementara itu, respon sistem pada referensi $43{ }^{\circ} \mathrm{C}$ (Gambar 7) menghasilkan tanggapan respon transien untuk waktu tunda (Td) sebesar 116 detik, waktu naik (Tr) sebesar 232 detik, waktu puncak (Tp) sebesar 310 detik, waktu penetapan (Ts) sebesar 1339 detik, dan maximum overshoot (Mp) yang dihasilkan dapat diperoleh melalui perhitungan dengan $(2.16)$ adalah $7,44 \%\left(5,4^{\circ} \mathrm{C}\right)$. 


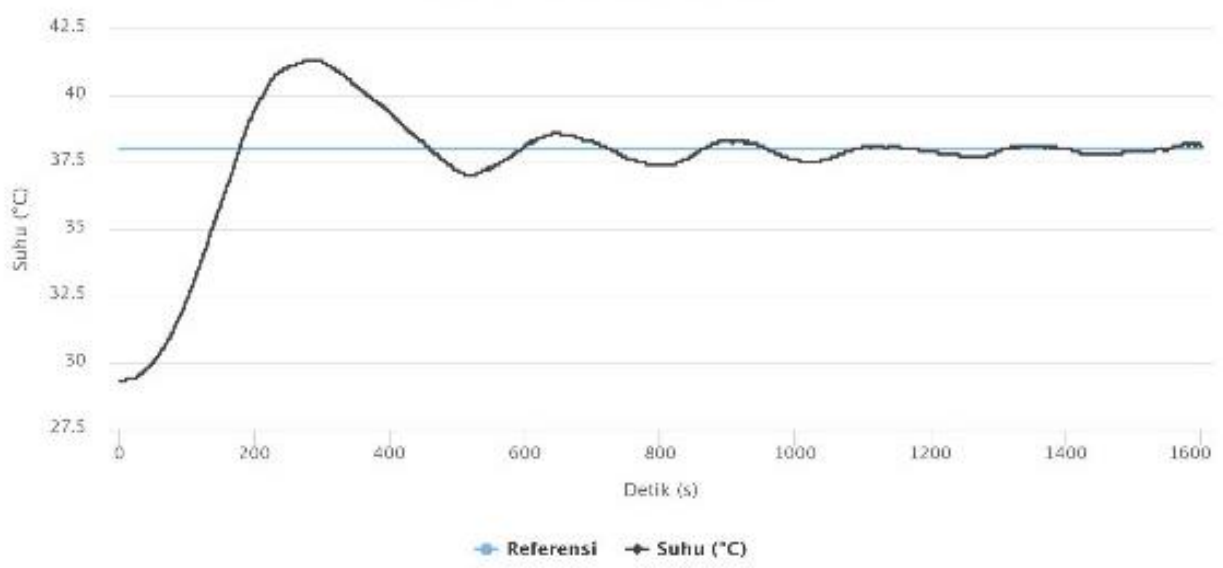

Gambar 5 Hasil pengujian respon sistem dengan referensi $38^{\circ} \mathrm{C}$.

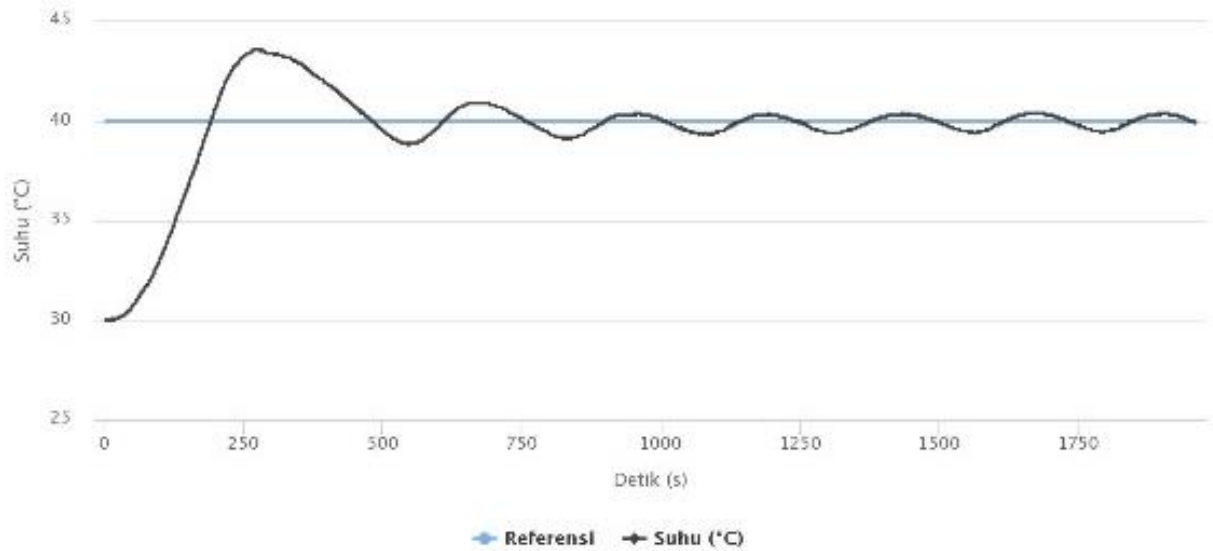

Gambar 6 Hasil pengujian respon sistem dengan referensi $40^{\circ} \mathrm{C}$.

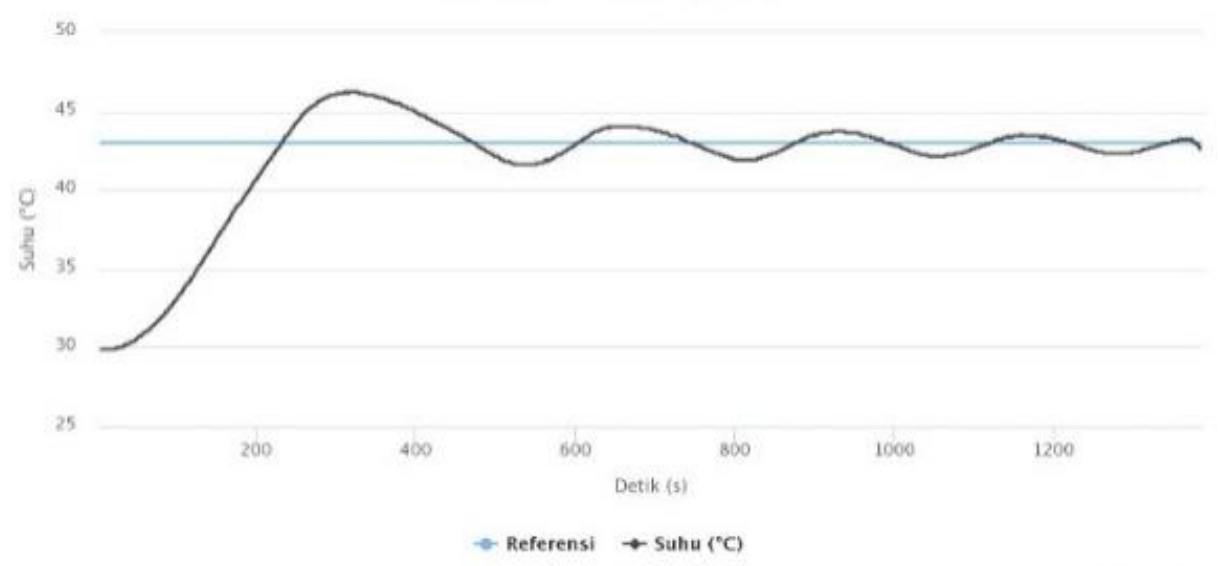

Gambar 7 Hasil pengujian respon sistem dengan referensi $43^{\circ} \mathrm{C}$.

Selain itu, dilakukan pengujian respon sistem dengan gangguan. Pengujian dilakukan dengan membuka tutup plant pengering (sebesar $20^{\circ}$ dari engsel pintu plant) selama 300 detik ketika sistem telah mencapai keadaan stabil. Hasil pengujian respon sistem dengan gangguan ditunjukkan pada Gambar 8. 


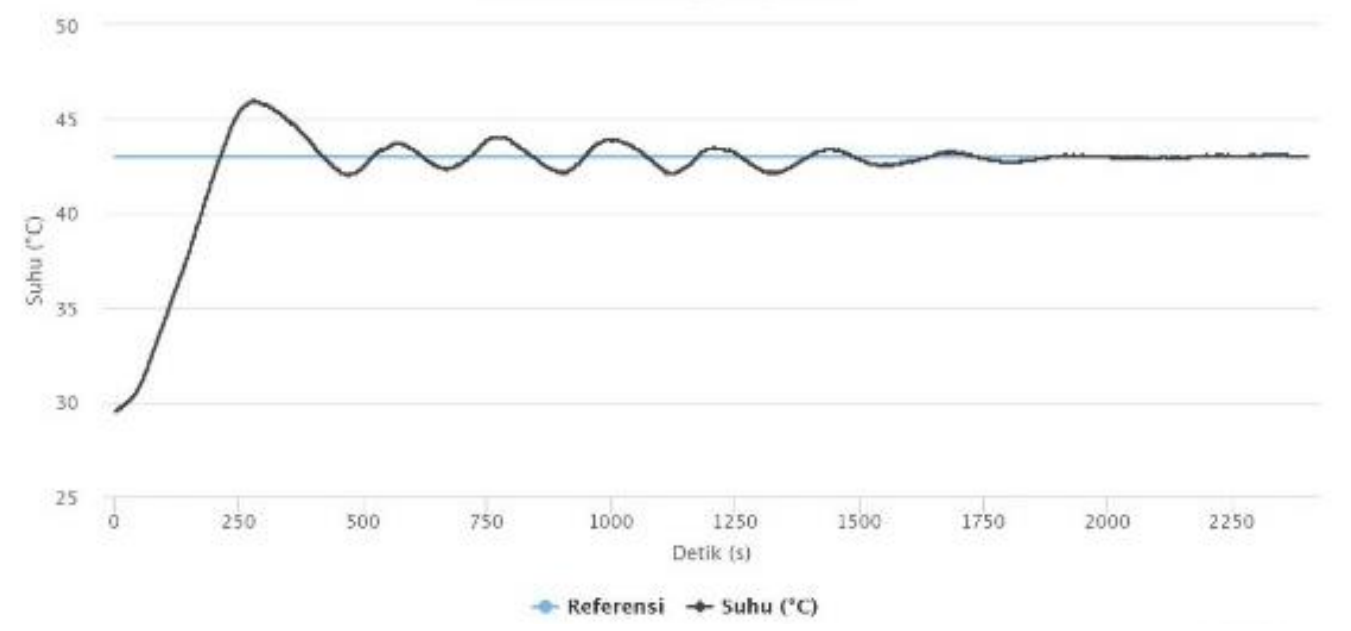

Gambar 8 Hasil pengujian respon sistem dengan gangguan

Pada Gambar 8 terlihat bahwa respon suhu sistem pengendalian suhu dengan gangguan terus menerus untuk referensi $43^{\circ} \mathrm{C}$ sulit untuk mencapai kondisi stabil pada referensi yang diberikan. Saat respon suhu mencapai $42,1^{\circ} \mathrm{C}$ pada detik ke-1328, maka gangguan diakhiri yaitu dengan menutup pintu plant. Setelah pintu ditutup rapat, respon suhu mulai naik mengikuti referensi dan mencapai setpoint memerlukan waktu 320 detik, dan pada detik ke-1648 respon sistem pengendali suhu sudah mencapai keadaan tunak.

Kendali PI pada purwarupa sistem pengeringan gabah ini telah menunjukkan kinerja yang baik, berdasar pengujian yang telah dilakukan. Respon tunda yang diperoleh cukup cepat, jika dibandingkan dengan lama pengeringan dalam orde jam. Pengeringan ini juga lebih cepat dibandingkan dengan pengeringan dengan matahari yang mencapai belasan jam [1]. Purwarupa ini juga telah berhasil menjaga suhu gabah agar memiliki pemanasan yang stabil, yang lebih unggul dibandingkan pemanasan dengan matahari, yang memiliki fluktuasi suhu yang tergantung pada waktu dan cuaca. Selain itu, profil suhu dari purwarupa pemanas ini telah menunjukkan kemampuan pemanasan di bawah $45{ }^{\circ} \mathrm{C}$, sesuai dengan rekomendasi suhu optimal [13]. Dengan demikian, sistem pengering ini dapat menghindarkan gabah dari kerusakan akibat pemanasan berlebih saat pengeringan, yang berakibat turunnya mutu beras saat diolah.

\section{Kesimpulan}

Berdasarkan pengujian dan analisis yang dilakukan dalam pengendalian suhu dan desain perangkat keras pada purwarupa pengering gabah menggunakan metode kendali PI berbasis mikrokontroler, disimpulkan bahwa sensor suhu memiliki galat pembacaan yang dapat diterima, sebesar $0,21{ }^{\circ} \mathrm{C}$. Secara keseluruhan pengujian kendali PI menggunakan parameter kendali $\mathrm{Kp}=$ 186,16 dan $\mathrm{Ti}=33,3$ hasil penalaan metode Ziegler Nichols 1 memiliki unjuk kerja yang baik karena mampu mencapai dan mempertahankan suhu plant pada referensi yang diinginkan. Sistem mampu mempertahankan suhu sesuai referensi meskipun terdapat perubahan referensi suhu serta dapat mengatasi gangguan yang terjadi. Pada rentang suhu optimum pengeringan gabah (38-43 $\left.{ }^{\circ} \mathrm{C}\right)$, berdasarkan pengujian sistem dengan referensi suhu tetap $\left(38^{\circ} \mathrm{C}, 40^{\circ} \mathrm{C}\right.$, dan $\left.43^{\circ} \mathrm{C}\right)$, diperoleh waktu tunda maksimum sebesar 116 detik, dan overshoot maksimum $7,44 \%\left(5,4^{\circ} \mathrm{C}\right)$. Nilai yang diperoleh ini baik dan dapat diterima, mengingat lama pengeringan dalam orde beberapa jam. Pengujian respon sistem dengan gangguan menunjukkan bahwa kendali PI mampu mengatasi ganguan dan dapat mengembalikan respon sistem ke referensi $43^{\circ} \mathrm{C}$ yang diberikan dengan waktu 320 detik. Dengan demikian, sistem pengendali suhu dengan kendali PI ini telah berhasil menunjukkan kinerja yang lebih baik dibandingkan dengan pengeringan matahari untuk sistem pengeringan gabah, berdasar kemampuan mencapai dan mempertahankan suhu referensi yang diinginkan serta dapat mengatasi gangguan yang terjadi dalam rentang suhu yang aman. 


\section{Referensi}

[1] Purwadaria HK, "Problems and priorities of grain drying in Indonesia. Dalam Grain drying in Asia," proceedings of an international conference held at the FAO Regional Office for Asia and the Pacific, Bangkok, Thailand: 17-20 October 1995

[2] Panggabean T, Triana AN, Hayati A, "Kinerja pengeringan gabah menggunakan alat pengering tipe rak dengan energi surya, biomassa, dan kombinasi," Agritech, 37(2), 229-35, 2017.

[3] Esehaghbeygi A, "Effect of electrohydrodynamic and batch drying on rice fissuring. Drying Technology," 30(14), 1644-8, 2012.

[4] Delele MA, Weigler F, Mellmann J, "Advances in the application of a rotary dryer for drying of agricultural products: A review," Drying technology, 33(5), 541-558, 2015.

[5] Widjanarko A, Ridwan R, Djaeni M, Ratnawati R, "Penggunaan Zeolite Sintetis Dalam Pengeringan Gabah Dengan Proses Fluidisasi Indirect Contact," Jurnal Teknologi Kimia dan Industri, 103-10, 2013.

[6] Yu KC, Chen CC, Wu PC, "Research on application and rehydration rate of vacuum freeze drying of rice," Journal of Applied Sciences, 11(3), 535-541, 2011.

[7] Darjat D, Syahadi M, Setiawan I, "Aplikasi Kontrol Proporsional Integral Berbasis Mikrokontroler ATMEGA8535 untuk Pengaturan suhu pada Alat Pengering Kertas," InProceeding, Seminar Ilmiah Nasional Komputer dan Sistem Intelijen (KOMMIT 2008) Auditorium Universitas Gunadarma, Depok: Gunadarma University, 20-21 Agustus 2008.

[8] Mustikoaji YG, Riyadi MA, Darjat D, "Monitoring Dan Kendali Suhu Pada Oven Kayu Untuk Efisiensi Proses Pengeringan Menggunakan Raspberry Pi," TRANSIENT, 6(3), 440445, 2017 Nov 9.

[9] Alamsyah I, Zaira JY, Rahmawati M, "Sistem Kendali PI untuk Pengendalian Suhu pada Oven Otomatis Ikan Salai," Jurnal Teknik Elektro dan Komputer, 2(2), 153-62, 2014 Oct.

[10] Hamzah MA, Setiyono B, Sumardi S, "Perancangan Plant Alat Pembuat Sirup Buah Otomatis Dengan Kontrol PI Sebagai Pengendali Suhu Cairan Berbasis ATMEGA16," TRANSIENT," 3(4), 664-669, 2015.

[11] Suprapto BY, Hikmarika H, Dwijayanti S, Purwanto P, "Aplikasi Perbandingan Pengendali P, PI, Dan PID Pada Proses Pengendalian Suhu Dalam Sistem Mini Boiler,” Amplifier, 3(2), 12-8, 2013.

[12] Setiawan I, "Kontrol PID Untuk Proses Industri. Elex Media Komputindo," 2013.

[13] Inprasit C, Noomhorm A, "Effect of drying air temperature and grain temperature of different types of dryer and operation on rice quality," Drying technology, 19(2), 389-404, 2001. 